\title{
Performances of Technology Transfer Activities of US Universities after Bayh-Dole Act
}

\author{
Ampere A. Tseng and M. Raudensky
}

\begin{abstract}
The activities and performance of university patenting and licensing are studied to gauge the effectiveness of the Bayh-Dole Act, which is the most influential pieces of US legislation on university technology transfer. Based on the raw data from five different sources, the annual numbers of the patents granted, the licenses signed, and the startup companies launched are analyzed. The correlation evaluations are performed for all data presented to quantify the trends at different time periods. It is found that the patenting and licensing activities in US universities slow down greatly after 2000 and remain actually flat until 2010, while the associate activities from 2010 to 2012 are active and strong again to the level in the period before 2000 and after the enactment of the Act. Some explanations on the differences found in the different data sources and different time periods are provided.
\end{abstract}

Index Terms-Bayh-Dole Act, commercialization, innovation, license, patent, startup, technology transfer, university.

\section{INTRODUCTION}

Since 1980, US Congress had passed a series of legislation to facilitate U.S. technological innovation to reverse the productivity slowdown in 1960's and 1970's [1]. Among them, the Bayh-Dole Act of 1980 [1], [2] should be one of the most influential pieces of legislation to impact the area of university technology transfer. Basically the Act provides the ownership to the intellectual properties (including patent, copyright, and others) arose from government-funded research to universities with the expressed purpose of encouraging the commercialization of innovative technologies through licensing or cooperative ventures between the university and industry. The ownership or the patent right is to provide the motivation, especially economic incentives, for a university to license or to give an exclusive or a non-exclusive right to a company. For this, the Act is commonly credited with starting the boom in university technology transfer. The technology transfer literature tends to divide the university programs into pre- and post-the Bayh-Dole Act [3], [4].

Following the enactment of the Bayh-Dole Act at the end of 1980, universities in U.S. have greatly expanded their technology transfer efforts, specifically in the activities of patenting and licensing. Recently, because of the growth of Internet commerce and the advances in digital, information,

Manuscript received November 6, 2013; revised January 10, 2014.

Ampere A. Tseng is with the Manufacturing Institute, Arizona State University, Tempe, Arizona USA 85287; School for Engineering of Matter, Transport and Energy, 501 E. Tyler Mall, ECG301, Tempe, AZ 85287-6106 USA (e-mail: ampere.tseng@asu.edu).

M. Raudensky is with the Brno University of Technology, Czech Republic (e-mail: raudensky@fme.vutbr.cz). and biogenetics technology, a broad range of entrepreneurial companies have been formed and the substances in technology transfer have changed greatly as compared to those in twenty or thirty years ago. For example, the patentability of biological materials and biomedical research tools as well as the technology transfer of digital data and computer software have emerged as hot issues in technology transfer only lately [5,6]. It should be useful to assess the recent influence of the Bayh-Dole Act on the university technology transfer in the current technology environment.

Consequently, the purpose of the present article is to study the activities of university technology transfer, especially the two major activities involved: patenting and licensing. In this paper, the impacts of the Bayh-Dole Act on the performances of patenting and licensing in US universities are quantitatively examined. The raw data obtained from five independent sources, including results from Mowery et al. [7] and Wong et al. [8], as well as the reports from AUTM [9], [10], USPTO[11], and NSF [12], [13], are examined and compared to each other to form the required data for further correlation analyses. Correlation results are used for the projection of the future trends of patenting and licensing activities as well as to confirm some earlier observations. The data used in the correlations include the numbers of the annual patents issued, licenses signed, and startup companies formed. The differences found among the correlation results in different time frames are further investigated to provide necessary explanations. Finally, concluding remarks are given to summarize the results presented with a future perspective of university technology transfer.

\section{PATENTING PERFORMANCE AND COMPARISON}

The university technology transfer has become increasingly important, given concerns regarding the university's desire to maximize the returns to its intellectual property, especially the patents it owns. Patents and licenses are the necessary requirements for the success of technology transfer. In this section, the activities and trends of university patenting are studied, while the licensing and startup launching activities are analyzed in the next section.

\section{A. Patenting Share before and after Bayh-Dole Act}

Mowery and Sampat [7] performed a survey of the US patents issued to US research universities for the calendar years from 1963 to 1999 . The university patenting shares, which are the numbers of the annual US patents issued to US research universities divided by the respective number of the annual patents issued by USPTO to the domestic (US) assignees can be calculated and plotted in Fig. 1. The reasons 
to use the patenting shares defined above to gauge the impact of the Bayh-Dole Act are two: one is to remove the effects of increased patenting by non-US firms or inventors [11] and the other is to eliminate the effects of the patent increase by the changes of the economic environment. As shown in Fig. 1 , the university patent share increases almost monotonically every year, from about $0.2 \%$ in 1963 to nearly 4\% by 1999 . A correlation analysis is performed to quantify the growth rate of the patent share. The correlation parameters shown in Fig. 1 indicates that the annual growth rate or the slope of the correlation line from 1963 to 1981 is constant at $0.04 \%$ while the growth rate jumps to $0.16 \%$ from 1982 to 1999 , which is four times higher than that of the period from 1963 to 1981. This jump or acceleration of the patent-share growth rate should be attributed to the Bayh-Dole Act, which was enacted into law at the end of 1980. It is expected that the Act effect on patenting becomes noticeable after 1981 or 1982, since it would take at least a year to process a US patent application. As shown, the acceleration of the share rate increase after 1981 is significant, although some investigators argued that the increase in university patenting and licensing activities should also contribute to the economic boom of the 1990s. However, it is believed that the economic boom of the 1990s should benefit to all sectors of the society. The total number of patents can increase due to an economic boom while the patent share should be less affected by the economic boom, which is one of the main reasons to analyze the university patent share in the present study, as mentioned earlier.

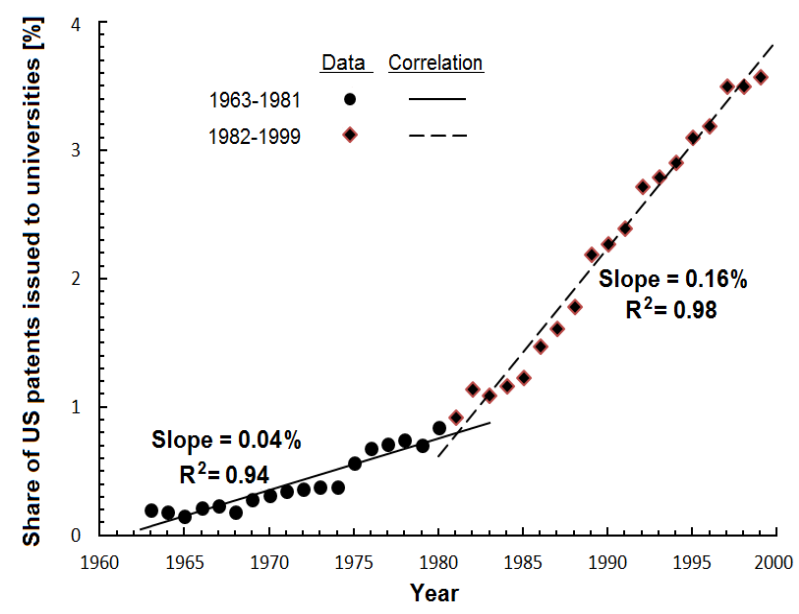

Fig. 1. Correlations of university patent share of U.S. patents, 1963 - 1999, with raw data from Refs [7] and [11].

Based on the data obtained from USPTO [11], Wong and Singh [8] studied the total patents annually issued by US government to 103 universities for the time span from 1977 to 2005. Among these 103 universities, 86 are from USA and 17 are in Canada; they are all leading research universities ranked by both the ARWU (Academic Ranking of World Universities) [15] and the WUR (World University Ranking) [16]. The university patenting data reported by Wong and Singh [8] are again normalized by the annual number of the total domestically assigned $\mathrm{U} S$ patents to obtain the university patent share. The results obtained and the associated correlation is all shown in Fig. 2. As shown, the annual growth rate of the patent share can be linearly correlated in two time frames: from 1977 to 1982 and from 1983 to 1999 and is non-correlative or inclusive in the period from 2000 to 2005 . The corresponding annual growth rate shown is $0.07 \%$ for the time span from 1977 to 1982 and leaps up to $0.14 \%$ for the period of 1983 to 1999 , which are consistent with the findings shown in Fig. 1, i.e., the university patenting activities are booming after 1982 and indeed due to the Bayh-Dole Act.

For the period of 1977 to 1981, the share growth rate depicted in Fig. 2 is about $40 \%$ higher than that shown in Fig. 1 ; this difference could be due to the fact that the survey population is too small ( 5 data points) in Fig. 2 and that the $20 \%$ of the universities surveyed are from Canada. On the other hand, from 1983 to 1999, the growth rate in Fig. 2 is about $12 \%$ lower than that shown in Fig. 1; this lower growth rate should be again caused by the 17 Canadian universities since they are not affected by the Bayh-Dole Act and their growth rates should be still the same as that in the period between 1977 and 1982, i.e., say 7\%. This argument can be proved by the following simple calculation, i.e., $20 \%$ universities having a growth rate of 0.07 plus $80 \%$ universities having a growth rate of 0.16 can yield that the growth rate for the total (100\%) universities becomes 0.142 , which the exact value is shown in Fig. 2. This calculation further confirms that the growth rate of university patenting share should be approximately $16 \%$ during the period of 1983 to 1999.

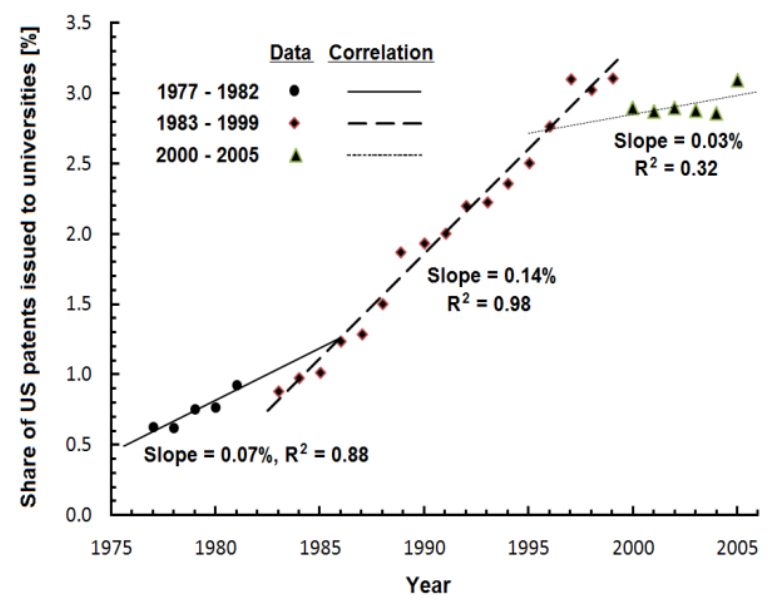

Fig. 2. Correlations of university patent share of U.S. patents, 1977 - 2005, based on raw data from Ref. [8] and [11].

In the correlation analysis, the corresponding coefficient of determinations $\left(R^{2}\right)$ shown in Fig. 1 and Fig. 2 are computed to quantify the data fitting accuracy. The $R^{2}$ coefficient is an overall measure of the deviation of a correlation regression to quantify how good the correlation curve (or function) to represent the data is. The coefficient always lies between 0 and 1 . A value of zero occurs when the two variables are totally independent of each other, while it reaches 1 when the two variables correlate perfectly, i.e., no deviation from the correlated curve [17]. As shown in Fig. 1, the corresponding $R^{2}$ for the correlations before and after 1981 are 0.94 and 0.98 , respectively, which imply that the patent share data fit the correlation extremely good with a maximum deviation less than 6\%. Similarly, in Fig. 2, 
between 1983 and 1999, the $\mathrm{R}^{2}$ is 0.98 indicating the correlation accuracy is exceedingly well. On the contrary, between 2000 and 2006, $R^{2}=0.32$, which means the data cannot be correlated accurate enough or can only be correlated with a very low accuracy.

\section{B. University Patenting Trends after 1999}

As discussed earlier and indicated in Fig. 2, the growth rate versus the time span from 2000 to 2005 cannot be correlated well by an appropriate curve and the annual patent data is irregularly fluctuated, where the university patent share decreases from $3.11 \%$ in 1999 to $3.09 \%$ in 2005 with a negative increase average rate. By studying Wong and Singh's data [8], Leydesdorff and Meyer [14] claimed that the decline of university patent numbers after 1999 signaled "the end of the Bayh-Dole effect" and suggested that the incentives for university patenting due to the Bayh-Dole Act disappeared with the new emphasizing on the university ranking, where patents and licenses were not counted in university rankings. However, this reason cannot explain the decrease of the patenting incentive in the beginning period of 2000s, because the college ranking starts to become noticeable or important to universities is after the middle of 2000s. Most of the important ranking surveys started in the middle of 2000s. For example, US News \& World Report started to publish its university ranking in 1983, which has become the most widely quoted ranking in the U.S. [18]. The ARWU has been compiled since 2003 [15] while the WUR began in 2004 [16].

By compiling the data from the 18 survey reports published by AUTM $[9,10]$, the annual numbers of the US patents issued to the US universities and non-profit research organizations from the fiscal year (FY) 1993 to 2012 are plotted in Fig. 3. Here, the non-profit research organizations are mainly medical research centers affiliated with hospitals, which are treated as same as the universities in the Bayh-Dole Act; they are normally less than $20 \%$ of the AUTM survey populations. As indicated in Fig. 3, the increase of the patents annually issued can be linearly correlated very well with two time frames, from 1993 to 1999 and from 2010 to 2012. In these two frames, the patents annually granted increase every year with 1,530 patents granted in 1993 and 3501 patents in 1999 as well as with 4,459 patents issued in 2010 and 5,145 patents in 2012. The corresponding two growth rates are almost equal and are 331 and 338 patents per year for the periods from 1993 to 1999 and from 2010 to 2012, respectively.

From 2000 to 2009, on the other hand, the annual patent numbers are randomly fluctuated and can only be correlated with a linear function with a low accuracy. Nevertheless, the average increase patent rate can be found to be negative and the number of patents basically decreases 31 patents per year as shown in Fig. 3. This finding is similar to that shown in Fig. 2 for the time frame from 2000 to 2005 and this further confirms that the university patenting trend after 2000 is quite different from that before 2000. Also, it is interesting to point out that the university patenting activities after 2009 show significant rise in the number of issued patents and remain very strong in the past few years.

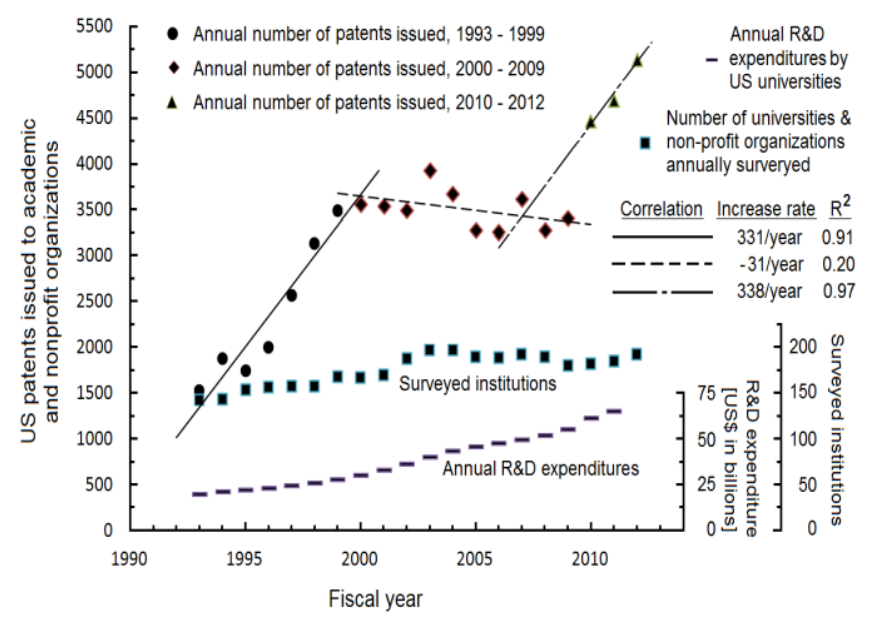

Fig. 3. Annual US patents granted to academic and non-profile organizations from 1993 to 2012, with comparison of the total annual R\&D expenditures with raw data from AUTM [9], [10], USPTO [11], and NSF [12], [13].

Originally, it was suspected that the fluctuation could be due to the inconsistence of the survey population. However, after carefully examining the total numbers of the institutions surveyed by AUTM in each year, which are also depicted in Fig. 3, any correlation between the number change of the institutions surveyed and the fluctuation of the annual patents issued between 2000 and 2009 cannot be found. The number of the institutions plotted in Fig. 3 has been adjusted by eliminating the contributions of the organizations for profit making.

The possible cause by the variation of the research funding on the fluctuation of the annual patents granted is also assessed. For the convenience of the assessment, the total annual R\&D expenditures for US universities reported by US National Science Foundation [12], [13] are also depicted in Fig. 3, where the expenditures are monotonically increasing from FY1993 to FY2011 and no fluctuation or abruption was found. Consequently, the expenditure variation should not cause the fluctuation of the annual numbers of the patents issued from FY2000 to FY 2009. Other causes, such as the dot.com bubbling occurring 2010 [19] and the housing bubbling occurring 2007, which is the primary cause of the 2007-2009 recession in the U.S. [20], are also suspected for the fluctuation. Although the timing is right, no rigorous studies or direct evidences can be found to support these suspected reasons. Further studies of the causes of the fluctuation of the patents issued in 2000s should be encouraged.

\section{Prospective Changes of University Patenting After 2013}

Recently, the Leahy-Smith America Invents Act (AIA) was signed into law and became effectively on March 16, 2013 [21]. The law represents the most significant change to the U.S. patent system since 1952. The law switches U.S. rights to a patent from the previous "first-to-invent" system to the present "first inventor-to-file" system and also expands the definition of prior art (such as including foreign offers for sale and public uses) used in determining patentability. Making a disclosure before a patent filing is extremely risky. It can no longer antedate or swear behind another's work, so make sure that any patent application should be filed as early 
and as completely as possible. The AIA Act may bar a patent if any of the following occur before the effective filing date (EFD): a) invention described in a printed publication, b) invention placed in public use, c) invention placed on sale, d) invention otherwise made available to the public, or e) invention described in issued US patent or published US patent application naming another inventor and having an EFD before the EFD of the relevant patent or application.

As indicated by Fox [22], the AIA Act would simplify the application process and bring U.S. patent law into better harmony with the patent law of other countries, especially in European Union, most of which operate on the "first-to-file" system. Proponents also claimed that it would eliminate costly interference proceedings at the USPTO and reduce U.S. applicants' disadvantages in seeking patent rights outside of the U.S. On the contrary, opponents, including Nesheim [23], argued that the AIA act would prevent startup companies, a potent source of inventions, from raising capital and being able to commercialize their inventions. Typically, an inventor would have a sufficient conception of the invention and funding to file a patent application only after receiving investment capital. Before receiving investor funding, the inventor must have already conceived the invention, proven its functionality, and done sufficient market research to propose a detailed business plan. Investors will then scrutinize the business plan and evaluate competitive risk, which is inherently high for a startup company as a new entrant into the market. Critics expressed concern that, venture funding now would be diverted to less risky investments. The impact of AIA on the university patenting activities should be noticed in the very near future.

\section{LICENSING AND STARTUP ACTIVITIES}

The licensing of university intellectual property or, more specifically, active patents is the major revenue for university technology transfer. As a result, the licensing activities are essential to a successful technology transfer. In this section, the university licensing activities, especially the annual numbers of the licenses signed and startups launched are analyzed and the associated trends are determined.

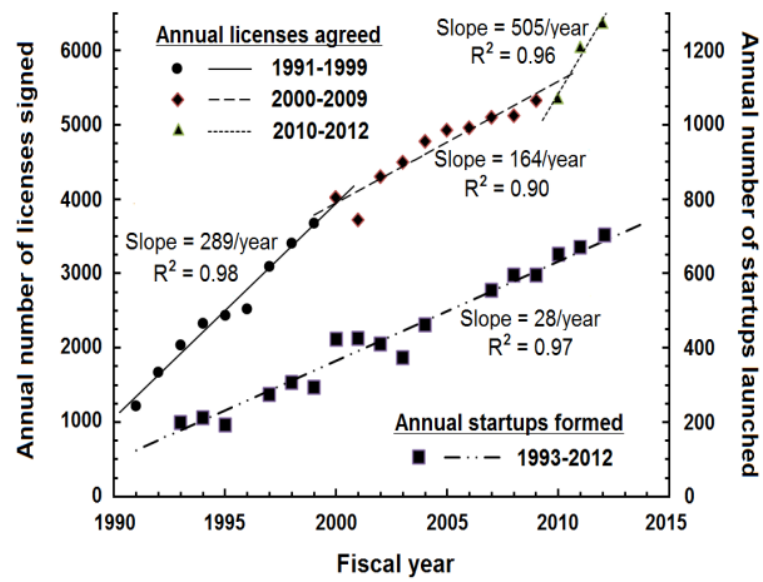

Fig. 4. Annual licenses signed and startup companies formed by academic and non-profile research organizations with raw data from AUTM [9], [10].

\section{A. University Licenses Executed}

According to AUTM annual surveys from 1991 to 2012, the university licenses executed increased by more than $500 \%$ with a total of 87,102 executed over the entire period, where 1,229 license agreements signed in 1991 and 6,372 licenses in $2012[9,10]$. A correlation analysis is performed with the AUTM data and the results are depicted in Fig. 4. As indicated in the figure, the annual numbers of the licenses signed by the AUTM survey respondents can be distinguished into three time zones: from 1991 to 1999 , from 2000 to 2009 , and from 2010 to 2012 . As shown, the license growth rate between 2000 and 2009 is lower than that of 1991 to 1999 and of 2010 to 2012, the license numbers show a health growth between 1991 and 1999 with an average increase rate of 289 per year, which is $76 \%$ higher than that between 2000 and 2009. Between 2010 and 2012 or in the past three years, the university licensing activities are recovered with an increase rate even higher than that between 1991 and 1999 at an average increase rate of 505 per year.

Interestingly, the three time zones shown in Fig. 4 are coinciding with the three time frames found for the US patent correlation shown in Fig. 3, but with one feature is different, i.e., the license numbers can be correlated well in the period between 2000 and 2012 with $R^{2}=0.90$, while the patent numbers cannot be correlated accurately with $R^{2}=0.20$. As a result, the factors, which can influence the university patenting activities, seem to have less effect on the university license performance. These factors, however, are unclear and remain to be studied.

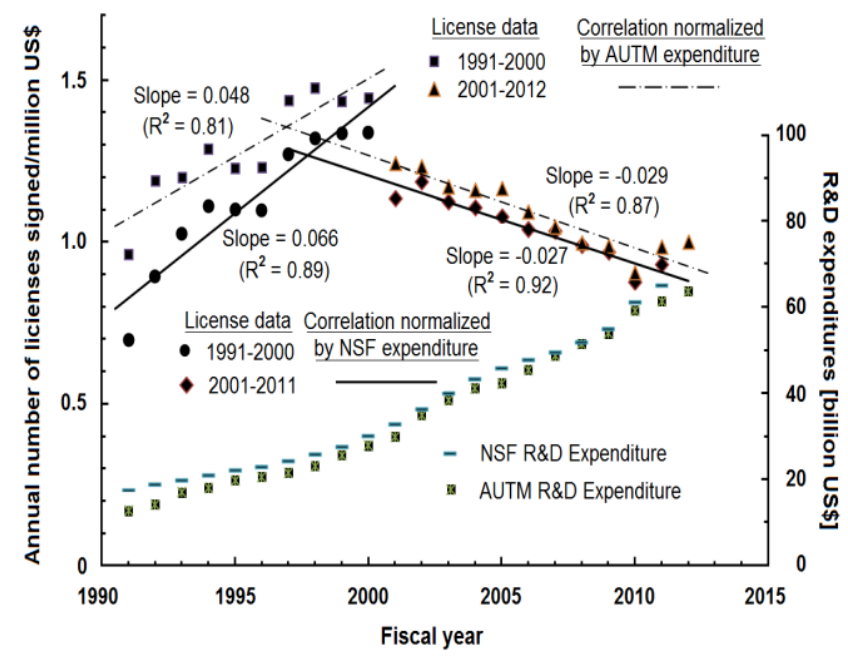

Fig. 5. Annual licenses per $\$ 1$ million of R\&D expenditures from FY1991 to FY2012 based on data from AUTM [9], [10] and NSF [12], [13].

Because of the importance of the university innovation to industry, to the allocation of research resources, and to policy decisions, many stakeholders in university technology transfer, such as academic researchers, technology transfer offices, policy-makers, and private industry, should be interested in knowing the impact of university research expenditures on the number of the licenses agreed [24], [25]. The licensing data shown in Fig. 4 are normalized by R\&D expenditures and the resulted normalized data are plotted in Fig. 5. Two sets of R\&D expenditure data used for normalization are also depicted in Fig. 5, where one was reported by NSF [12], [13] while the other was obtained from the surveys by AUTM [9], [10]. As shown, the NSF reported expenditures for all US research universities grow 
monotonically from 17, 6 billion dollars in FY1991 to 65.1 billion dollars in FY2011; the average growth rate is approximately 2.35 billion dollars per year. The total expenditures reported by the academic and research members of AUTM are 12.8 billons dollars in FY1991 and 63.7 billion dollars in FY2012, where the annual increase rate is 2.48 billion, which is about $6 \%$ higher than that of NSF expenditures. Roughly speaking, the NSF reported expenditures are about $10 \%$ higher than the corresponding AUTM surveyed values and, for more resent data, the difference is even smaller. For example, between 2000 and 2011, the average difference is less than 5\%. Since the research expenditures reported by AUTM in more recent surveys are so close to that of the total expenditures from all US research universities reported by NSF, the technology transfer data reported by AUTM should be expected to be pretty much close to the data for all US research universities with a possible inaccuracy within $5 \%$.

As shown in Fig. 5, the number of licenses signed relative to the NSF research expenditures increased from 0.70 licenses per \$1 million expenditures in FY1991 to 1.34 in FY2000 with a normalized license growth rate of 0.066 licenses per $\$ 1$ million per year, while the license number normalized by the AUTM expenditures increases from 0.96 licenses per $\$ 1$ million in 1991 to 1.44 in 2000 with the growth rate equal to 0.048 licenses per $\$ 1$ million per year. In general, the results based on both data sets indicate that the normalized license number has a health growth from 1991 to 2000 and the increase of the normalized license number is reasonably strong. However, as shown in Fig. 5, after 2000, the normalized license number decreases and the growth rate becomes negative between - 0.027 and -0.029 licenses per \$1 million expenditures per year. This negative trend is especially interesting because if the annual license numbers are not normalized by the research expenditures, the associate growth rate is still positive although the associated increase rate is much lower than that before 2000. As a result, whether the trend of the license activities after 2000 having a moderate growth or having a decline is still inconclusive, since the trend after 2010 is relatively vague and only three data points are available for correlation, which are too little to draw a reliable projection. More data or studies are needed to reach a more solid conclusion.

The $R^{2}$ coefficients obtained for the four correlations shown in Fig. 5 varies between 0.81 and 0.92 , which are within an appropriate range, i.e., the correlations are reasonable reliable, although higher $R^{2}$ values could be better.

\section{B. University Startup Companies Launched}

The numbers of the startup companies created annually by US universities and research organizations reported by AUTM [9], [10] are analyzed. The associated results are depicted in Fig. 4 for the time span from 1993 to 2012 and indicate that the startup companies created increase by $353 \%$ from 201 at 1993 to 705 companies at 2012. As shown in Fig. 4 , the correlation line illustrates that the annual startup numbers can be reliably correlated linearly with the entire time span considered with $\mathrm{R}^{2}=0.97$. The growth rate of startups launched can be found to be 28 startups per year, a health growth rate. To find the correlation between the research expenditure and the number of the startup companies created, the annual numbers of the startup companies are normalized by the AUTM research expenditures. The results with associated correlation are shown in Fig. 6. It was surprised to find that the normalized data cannot be correlated well as shown the $R^{2}$ coefficient is barely 0.06 , which implies that it is $94 \%$ that the annual numbers of startup companies created are not correlated with the annual research expenditures. In normalizing the annual startup numbers, the AUTM R\&D expenditures is adopted, since the expenditures reported by NSF is not much different from that of AUTM and should not be repeated here.

As indicated in Fig. 3, the number of the institutions surveyed by AUTM varies from 143 to 197 in the period between 1993 and 2012. To eliminate the effects of the inconsistent numbers of the surveyed institutions on the survey accuracy, the normalized annual startup numbers are further divided by the numbers of the institutions surveyed and the results are also plotted in Fig. 6. As shown, the fitness of the data to the correlation is better than that without considering the influence of the numbers of the institutions surveyed but the improvement is not too much. The double normalized startup data still cannot be correlated well with the time span, considered where the $R^{2}$ coefficient equals 0.15 , which is still too low to have a reliable correlation. This re-confirms the earlier finding that no relationship can be found between the annual numbers of the startup companies created and the annual research expenditures. It may be due to the fact that the numbers of startups launched by universities are relatively small and are one-order magnitude less than that of the patent granted or licenses agreed. Because of such small startup numbers, the incentives for increasing the startup companies could be much different from that for patenting and licensing. Consequently, the characteristics of the university startup related activities can be quite different from that of patenting or licensing, as those shown in Fig. 4.

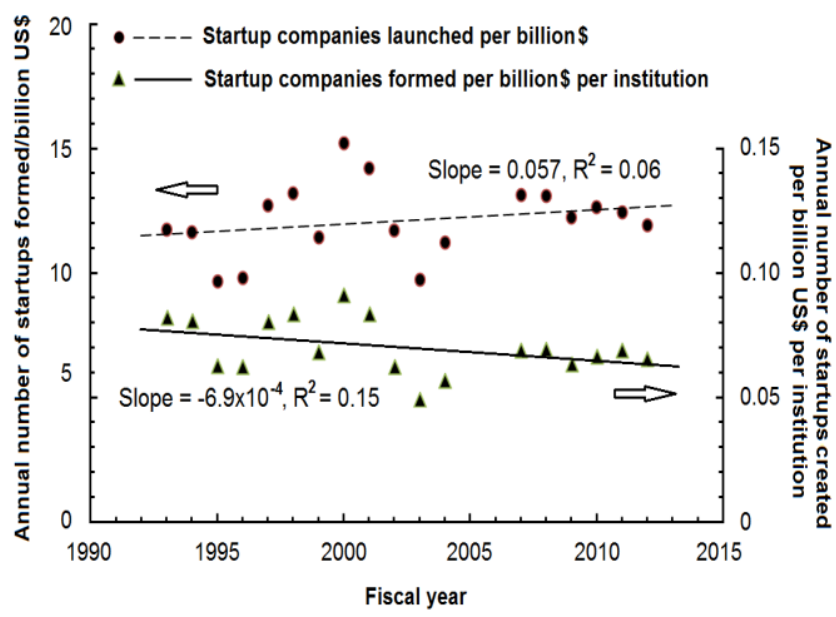

Fig. 6. Annual startup companies per $\$ 1$ billion of R\&D expenditures and per $\$ 1$ billion expenditure per institution surveyed from FY1993 to FY2012 based on raw data from AUTM [9], [10].

\section{CONCLUDING REMARKS}

The present study quantifies the effect of the Bayh-Dole 
Act by using patenting and licensing as the indicator or trend-predictor. In general, the benefits created by the Bayh-Dole Act greatly outweigh any possible negative consequences. As indicated in the results studied, the Act was built quite soundly to allow incentives for all involved parties (government, academia, industry), but also has safety measures to ensure that the inventions are handled correctly in the past thirty years. It has been found that appropriate legislation, such as the Bayh-Dole Act, can provide strong enough incentives to encourage universities to deliver a pipeline of creativity and innovation to work with industry to make the university technology transfer successful.

The annual numbers of the patents granted, licenses signed, and startups launched are separately analyzed and the associated growth rates are studied. Raw data from five different sources are evaluated and correlated at different time frames. It has been found that the growth rate of the university patenting as a share of domestically assigned US patents after the Act enacted is in three to four times higher than that before. However the patent growth rate slows down greatly after 2000 and remains actually flat until 2010. The university patenting activities from 2010 to 2012 are active and strong again to the level in the period from 1982 to 1999 with an increase rate of 338 patents per year. Since only 3 correlation data between 2010 and 2012 are available, the prediction of the trend after 2012 may be premature. The future data (after 2012) on the university patenting might be needed to confirm this projection.

It has been found that the licensing activities in US universities also slow down in the time period between 2000 and 2010 and the growth rate of the licenses executed is less than $60 \%$ of that of the time span between 1991 and 1999. After 2010, the annual number of the licenses signed shows strongly recovered. Again it may be still premature for the trend projected after 2012. Note that, to eliminate the effect of the continuously increased research funding, the number of annual licensing signed is normalized by the university research expenditure and the normalized licensing number shows decrease in the time frame between 2001 and 2010 at a decrease rate of approximately 0.028 licenses per $\$ 1$ million per year.

The causes for the continuous weakness of the university patenting and licensing activities between 2000 and 2010 could be related to economic environment. It is suspected that dot.com bubbling occurring 2010 and the housing bubbling occurring 2007, which is the primary cause of the 2007-2009 recession in the U.S., could be the two major causes for the weakness of university technology transfer during this period. However, the timing may be right, but no solid evidences are found to support these two suspected reasons.

On the other hand, the number of startups launched remains active for the entire period from 1993 to 2012 and increases monotonically from 201 startup companies at 1993 to 705 companies at 2012 at an increase rate of 28 companies per year. The reasons for the different behaviors of licensing and startup activities in the period between 2000 and 2010 may be due to the fact that the numbers of startups launched are significantly small, which are one-order magnitude less than that of the patent granted or licenses agreed.
Consequently, the incentives for increasing the startup companies could be different from that for patenting and licensing.

Further studies to provide more explanation on the softness of the university patenting and licensing performances between 2000 and 2010 and the recovered strong trend of the patenting and licensing activities after 2010 should be encouraged. Particularly, it is essential to all involved parties to know whether the economic environment or some other types of incentives are involved, so that better strategies or legislation can be proposed. Note that the current economic condition has changed greatly and is much different from the time when the Bayh-Dole Act was introduced. One thing for sure is that the huge growth of technology transfer activities cannot continue forever; the final equilibrium and associated trend, however, remain to be seen.

\section{ACKNOWLEDGMENT}

The authors acknowledge the generous funding by Czech Ministry of Education, Youth and Sports (Project No. HEATEAM - CZ.1.07/2.3.00/20.0188). This funding also provides the government endowed professorship to the first author at Brno University of Technology (BUT) from 2012 to 2013 to perform the study. Special thanks are to Mr. Jan Kominek and Ms. Hana Hladilova of BUT for their assistance in preparing this article.

\section{REFERENCES}

[1] A. Stevens, "The enactment of Bayh-Dole," J. Technology Transfer, vol. 29, pp. 93-99, 2004.

[2] W. H. Schacht, "The Bayh-Dole act: selected issues in patent policy and the commercialization of technology," CRS Report for Congress, Congressional Research Service, Washington DC, no. RL32076, 2012.

[3] D. C. Mowery, R. R. Nelson, B. N. Sampat, and A. A. Ziedonis, Ivory Tower and Industrial Innovation: University-Industry Technology Transfer Before and After the Bayh-Dole Act, Stanford University Press, Redwood City, CA 2004.

[4] R. L. Geiger, "Ivory tower and industrial innovation: university-industry technology transfer before and after the Bayh-Dole Act (review)," Review of Higher Education, vol. 29, no. 1, pp. 130-131, 2005.

[5] B. M. Knoppers, "Status, sale and patenting of human genetic material: an international survey," Nature Genetics, vol. 22, pp. 23-26, 1999.

[6] J. E. Cohen and M. A. Lemley, "Patent scope and innovation in the software industry," California Law Review, vol. 89, no. 1, pp. 1-57, 2001.

[7] D. Mowery and B. Sampat, "The Bayh-Dole Act of 1980 and university-industry technology transfer: a model for other OECD governments?" J. Technology Transfer, vol. 30, no. 1/2, pp. 115-127, 2005.

[8] P. K. Wong and A. Singh, "University patenting activities and their link to the quantity and quality of scientific publications," Scientometrics, vol. 83, no. 1, pp. 271-294, 2010.

[9] AUTM. Licensing Surveys: 1991-2005. Association of University Technology Managers. 1996-2006. Deerfield, IL, USA. [Online]. Available: http://www.autm.net/Surveys.htm

[10] AUTM. Licensing Activity Survey: 2006-2012. Association of University Technology Managers. 2007-2013. Deerfield, IL, USA [Online]. Available: http://www.autm.net/Surveys.htm

[11] USPTO. U.S. Patent Statistics. Calendar Years 1963 - 2012. The United States Patent and Trademark Office. Alexandria, VA. [Online]. Available:

http://www.uspto.gov/web/offices/ac/ido/oeip/taf/us_stat.htm

[12] R. Britt. (July 2011). Academic research and development expenditures: fiscal year 2009. Rep. No. NSF 11-313. US National Science Foundation. Alexandria. VA. [Online]. Available: http://www.nsf.gov/statistics/nsf11313/ 
[13] R. Britt, "Universities report highest-ever R\&D Spending of $\$ 65$ Billion in FY 2011," Rep. No. NSF 13-305, US National Science Foundation, Alexandria, VA, November 2012.

[14] L. Leydesdorff and M. Meyer, "The decline of university patenting and the end of the Bayh-Dole effect," Scientometrics, vol. 83, no. 2, pp. 355-362, 2010

[15] ARWU. (Sept. 15, 2013). Academic Ranking of World Universities. Surveyed by Shanghai Jiao Tong University, Shanghai. China. [Online] Available: http://www.shanghairanking.com

[16] WUR. World University Ranking reported by Times Higher Education. London, United Kingdom. [Online]. Available: http://www.timeshighereducation.co.uk/world-university-rankings

[17] A. A. Tseng, M. Raudensky, and B. Li, "Impingement flux uniformity in nozzle spraying for industrial applications," Atomization and Sprays, vol. 23, no. 9, pp. 819-840, 2013.

[18] Best College Rankings. US News \& World Report. New York, NY. [Online]. Available: http://www.usnews.com/rankings

[19] A. Razin and S. Rosefielde, "Currency and financial crises of the 1990s and 2000s," CESifo Economic Studies, vol. 57, no. 3, pp. 499-530, 2011

[20] J. Holt, "A summary of the primary causes of the housing bubble and the resulting credit crisis: a non-technical paper," J. Business Inquiry, vol. 8 , no. 1 , pp. 120-129.

[21] H. R. 1249. America Invents Act. [Online]. Available: http://www.uspto.gov/aia_implementation/bills-112hr1249enr.pdf. Retrieved May 1, 2013

[22] J. L. Fox, "America invents act receives cautious welcome," Nature Biotechnology, vol. 29, pp. 953-954, 2011.

[23] J. L. Nesheim, "High tech start up," The Complete Handbook for Creating Successful New High Tech Companies, The Free Press, New York, NY, 2000.
[24] J. G. Thursby and M. C. Thursby, "University licensing and the Bayh-Dole Act," Science, vol. 301, pp. 1052, 2003.

[25] J. B. Powers and P. McDougall, "Policy orientation effects on performance with licensing to start-ups and small companies," Research Policy, vol. 34, no. 7, pp. 1028-1042, 2005.

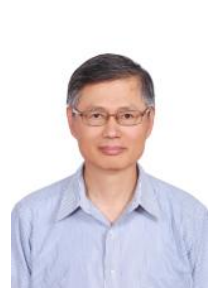

Ampere A. Tseng received his Ph.D. degree from Georgia Institute of Technology, USA in 1978. Currently, he is a professor and director emeritus of Manufacturing Institute at Arizona State University (USA) and Government Endowed Professor of Brno University of Technology (Czech Republic). Dr. Tseng has well-established records in publication and research funding in the area of the technology and business aspects of manufacturing. Over the past twenty years, he has published over one hundred fifty refereed journal articles, given more than two hundred invited talks or presentations, and edited more than ten monographs. Dr. Tseng has received more than three million dollars in research funding from government agencies and industries. Professor Tseng has developed several new techniques in macro- and micro-fabrication and was granted nine US and one non-US patents. He was bestowed an Honorary Guest Professor by Shanghai Jiao Tong University in 2000 and by Tsinghua University (Beijing) and University of Science and Technology of China in 2003. Dr. Tseng was also appointed as a University Chair Professor by National Taiwan University of Science and Technology (Taipei) in 2007 and National Tsinghua University (Hsinchu, Taiwan) in 2010, as well as the Government Endowed Professor by Brno University of Technology (Brno, Czech Rep.) in 2012. 